\title{
Molecular Studies on Microbiota in Raw Chicken's Meat in Jeddah Province
}

\author{
Abdullah A.K. Ghyathuddin 1,2, Abdullah Aljaddawi 1,3 \\ ${ }^{1}$ Department of Biological Sciences, Faculty of Science, King Abdulaziz University, Jeddah, 21589, Saudi Arabia. \\ ${ }^{2}$ Fakieh Poultry Farms, Makkah, Saudi Arabia. \\ ${ }^{3}$ Princess Dr. Najla Bint Saud Al-Saud Center for Excellence Research in Biotechnology, King Abdulaziz University, Jeddah, Saudi Arabia.
}

Correspondence Author: Abdullah A.K. Ghyathuddin, Department of Biological Sciences, Faculty of Science, King Abdulaziz University, Jeddah, 21589, Saudi Arabia.

E-mail: aghyathuddin@stu.kau.edu.sa

Received date: 28 August 2019, Accepted date: 15 December 2019, Online date: 28 December 2019

Copyright: (c) 2019 Abdullah A.K. Ghyathuddin, Abdullah Aljaddawi,,, This is an open-access article distributed under the terms of the Creative Commons Attribution License, which permits unrestricted use, distribution, and reproduction in any medium, provided the original author and source are credited.

\begin{abstract}
Foodborne illnesses are characterized as infectious or ototoxic illnesses caused by the bodily function of food or water infected by the World Health Organization (WHO). Foodborne illnesses are classified into giant towing, poisoning and infection teams. Poisoning is caused by pathogens' bodily function of the poison, throughout the infection, foods containing viable pathogens are locked up. the poison could also be a gift, although bacteria or other motive agents are not a gift, and by ingesting animals that have consumed poison-producing organisms, it is possible to develop food poisoning. Disinfectants are generally other than precooling water tanks in poultry processing plants to reduce contamination by microorganisms. The purpose of this analysis was to determine the microbiota of raw chicken meat in the province of Jeddah. This means that strict sanitary management measures must be applied to the biological phenomenon in order to improve sanitary conditions throughout the production, handling, storage and sale of food.
\end{abstract}

Keywords: food; Bacteria; Foodborne illness; Raw chicken meat.

\section{INTRODUCTION}

Drinking During the broiler carcass process, the evisceration, carcass washing, pre-cooling, and cooling stages will promote the spread of microorganisms and contamination of carcasses. An infected broiler entering the processing plant is also responsible for the contamination of many other carcasses [1]. Certain organisms present in the viscus of broiler chickens, such as enteric bacteria spp, Campylobacter spp, and thermotolerant coliforms, represent a threat to public health [2]. Carcasses will be contaminated jointly by spoilage microorganisms which reduce the period of meat production [3].

\section{Bacterial contamination in poultry meat:}

Consumption of poultry meat is steadily increasing worldwide; the latest market information indicates that it has reached fourteen, 2 weight units per capita per year [4]. Western developed countries, especially the US from America (USA), are the biggest customers, with 49.8 weight units per person per year [4]. A similar trend of increase in consumption is observed within the world organization (EU) and in the countries of the Organization for Economic Co-operation and Development (OECD). Similarly, use of poultry meat has doubled in France over the past thirty years and has become the second most consumed meat since 2012, reaching nearly twenty-six units of weight per capita in 2014 (close to consumption according to the EU) when pork (32.5 weight units per capita) [5]. Among poultry products, chicken carcasses, cuts, and processed products are the most consumed products ( $\sim 75 \%$ of total poultry meat), followed by Turkey $(\sim 25 \%)$ and, to a lesser extent, duck [6]. In France, the time for chicken meat is exhausted as contemporary cuts, generally in many modified atmosphere packaging (MAP). Vacuum packaging, MAP, cooling or marinades are entirely different practices to ensure a certain microbial quality throughout the storage of poultry cuts and depend on customers' habits and countries. Ensuring microbial safety of poultry meat is, therefore, a vital issue in this context of soaring consumption and production. In fact, throughout and during the slaughter, the bacteria of the animal microbiota, the atmosphere of the building and therefore the instrumentation used to contaminate the carcasses, their successive cuts and processed meat. A number of these microorganism contaminants will grow or survive throughout the process and storage of food. The resulting donation of microorganism communities in poultry meat will embody unhealthy species such as enteric and Campylobacter, the two main pathogens responsible for human inflammatory diseases caused by the consumption 
of poultry meat [7]. Since 2005, Campylobacter has been the main microorganism with ductal microorganisms in humans in the EU, wherever the number of cases confirmed according to in 2015 was 229,213 for human campylobacteria and ninety-four, 625 for human gastrointestinal disorders. Consumption of poultry has also been shown to be the main explanation for foodborne outbreaks in the United States between 1998 and 2012 [8]. Different ascending pathogens, such as Aeromonas sp., can also be considered [9]. In addition to foodborne pathogens, a bacterium responsible for spoilage could cause massive economic loss. Their growth and metabolic activity throughout the period leading to defects in color, odor, taste or texture are responsible for food waste and losses and therefore have a vital impact on the economy of the sector Poultry meat production.

\section{Food-Borne Bacteria Illnesses:}

Food poisoning syndrome results from the activity of water and a wide range of contamination of food by morbid organisms (bacteria, viruses, parasites, and fungi), their poison and chemicals. Gastrointestinal disturbances should be suspected once the acute care associated with canal or neurologic manifestation influences 2 additional people or animals who have shared a meal in the previous 72 hours. The commonly used term includes every food-borne infection and foodborne illness. Some microbiologists believe that microbial gastrointestinal disorders are different from foodborne diseases. In microbial gastrointestinal disorders, microbes multiply pronto in food before consumption, while in food-borne diseases, food is only the carrier of microbes that do not develop on their transient substrate. Different people consider gastrointestinal disorders as the poisoning of food with chemicals or toxins from bacteria or fungi [10].

Foodborne illness (FBI), commonly known as gastrointestinal upset, is caused by pathogens, although there are also harmless and helpful bacteria that do not produce dairy products, cheese. Some chemicals that cause foodborne illness are natural elements of food, while different chemicals are also accidentally inserted throughout production and the process, either through neglect or pollution. The main causes of foodborne illness are bacteria $(66 \%)$, chemicals $(26 \%)$, viruses $(4 \%)$ and parasites $(4 \%)$. the 2 most common types of foodborne illnesses are intoxication and infection. Poisoning occurs once the poison produced by pathogens causes gastrointestinal upset, while the infection is caused by the activity of foods containing pathogens [10, 11]. Some microorganisms will use our food as a source of nutrients for their growth. By growing on food, metabolizing it and making byproducts, they not only make food unpleasant but also create health problems when eaten. many of our foods can support the expansion of morbid microorganisms or a minimum of functional vector for its transmission. Food will be contaminated with the surfaces of plants, animals, water, wastewater, air, soil or food handlers throughout the handling and process $[10,13]$. The main causes of foodborne illness will be prevented through proper food preparation and process, which kills bacteria such as adequate refrigeration, improves personal hygiene, sufficient preparation or a method of heating food to warmer temperatures high and prevent the preservation of food in a warming device during the growth of bacteria temperatures [14].

\section{Salmonella:}

Etiology: The unit of the enteric bacteria zone consists of tiny, non-spore-forming, gram-negative rods that cannot be distinguished from escherichia under a magnifying glass or standard nutrient medium, they are cosmopolitan in nature, humans and animals being their main reservoirs. Enteric bacterial disease results from the absorption of food containing vital strains of this kind. Some critical changes have occurred in the taxonomy of enteric bacteria [15]. The zone unit \{genus enteric bacteria genus Salmonella | genus bacteria\} supposed to have 2 species called enteric bacteria and salmonella bongori. Serotyping differentiates the strain to which they refer, for example by S. enterica serotype Typhimurium or by S. Typhimurium [16].

Epidemiology: The first land of origin for enteric bacteria species is that the internal organs of animals such as animals, humans, birds, reptiles, and insects. Although their central terrain is the internal tract, they will occasionally be found in different parts of the. As a type of internal organ of associated degree, the surface unit of organisms is excreted in the excrement from which they will be transmitted by insects and different living creatures to a considerable amount of places [17, 18]. For medical functions, enteric bacteria are often placed in 3 groups; people in the primary zone unit who infect humans only. This includes S. Typhi, S. Paratyphi A, S. Paratyphi C. this group includes agents of typhoid fever and paratyphoid fevers, this area is the most serious of the diseases caused by enteric bacteria. The second was the host-adapted serotypes (some of these human pathogens from the surface unit and should be removed from food), the closed area unit S. gallirinuri (poultry), S. Dublin (cattle), S. abortusequi (equine), S. fetus - Ovis (sheep) and S. choleraesuis (pig). The third is that of unsuitable serotypes (no-host preference). There is a unit of morbidity for humans and different animals. The medical specialty of enteric bacteria is complicated, which often makes animal management of the disease difficult. The animal zone unites the reservoir of food from enteric diseases [19, 20].

Pathogenesis: Enteric bacteria generally enter the host by absorption, and even with many systems that mediate acid resistance, few survive the abdomen and enter the tiny viscus. The traditional flora protects against the formation of the administration of oral antibiotics facilitates the institution of the infection. The entry of enteric bacteria generally occurs without damaging the tissue layer in general infections, but the enteric infection is characterized by native damage while infection by septicemiasalmonella with $\mathrm{M}$ cells in the pay plates $\mathrm{n}$ is not accelerated by fimbrial adhesions. This can be followed by a ruffling of the target cytomembrane which leads to the acquisition of the microorganism in safe vacuoles of the membrane [21]. Ruffles facilitate the absorption of the microorganism into vacuoles or membrane vesicles that frequently coalesce. Organisms replicate in these vesicles and possibly free surface units of cells, which only undergo delicate or transient damage. The complicated invasion method is mediated by the commodity of various genes in the body, while growth inside a cell's host depends on the presence of virulence plasmids [22].

Symptoms: The time period of enteric bacteria is 12 to 36 hours. The clinical sign includes a symptom, which may be an aqueous, green, foul-smelling odor, this could be preceded by headache and chills. Different outcomes include prostration, 
muscle weakness, and moderate fever. In most cases, symptoms disappear within 2-3 days without complications [13]. The microorganism induces responses in the infecting animal, which can usually cause symptoms, instead of any direct toxic product. Unity of the usually ductal symptom zone, as well as nausea, vomiting, abdominal cramps and bloody symptoms with mucous membrane, headache, fatigue, and pink spots area. These symptoms are often severe, especially in young children and seniors. Symptoms usually last up to weekly and may appear 12 to 72 hours when ingesting the microorganism. Reactive inflammatory diseases combine with anemia and osteitis due to enteric bacterial infection are much more common than in the general population [18].

Detection of pathogens: The detection of enteric bacteria is often only accomplished by isolation of the agent from stool or vomit in humans, animal feed samples and samples involving foods such as milk and dairy product samples. In general, for culture and isolation, the use of selective enrichment media such as salmonella-shigella, agar, hektoen enteric agar or deoxycholate agar and broth for enrichment before subculture of these sugar agars when twenty-four hours is a standard procedure, selenite enrichment broth or tetrathionate broth are often used to isolate extremely selective for enteric bacteria, in particular, S. enterica serovar Typhi. Agar surface and plate unit incubated at $37^{\circ} \mathrm{C}$ long and growth known by organic chemistry tests and slide agglutination tests [21].

Prevention and control: The main sources of infection of animals carrying units from the infection zone and contaminated food containing food of animal origin. It is important to develop a technique to manage food spoilage or poisoning by standard enteric bacteria farms by instituting biosecurity and biological containment practices in addition to an increase in food processing techniques, preparation and storage [20].

Staphylococcus aureus:

Etiology: Cocci aureus are Gram-positive cocci that occur in singles, short chains, tetrads, and irregular grape clusters. only the strains that make the cytotoxin will cause disease. The food handler with a lesion or a vigorous port later triggers infection $[19,20]$.

Epidemiology: the host unit of the cocci species area is adapted to the common fraction of humans who live in the famous species alone and different animals. The most important figures are found near the deviation from the surface of the body like the anterior nostrils, regions, and regions wherein wet habitats the number per $\mathrm{cm} 2 \mathrm{can}$ reach 1000-1000000 and in dry habitats 10-1000. The 2 most vital sources for nasal units and people whose hand and arm unit has suffered boils and carbuncles, the zone unit of the United Nations agency is authorized to handle food [19]. Pathogenesis: if food is generally kept at temperature, the body can be found in food and can produce a toxic substance. The microorganism produces cytotoxin while multiplying in food. S.aureus intends to manufacture six types of serologically different enterotoxins (A, B, C, C2, D and E) which differ in toxicity. Most diseases are caused by cytotoxin followed by type D. These enterotoxin units are heat stable, with the blood group being the most heat resistant. Cytotoxin stimulates the central nervous systems (CNS) forcing the center and inhibiting the absorption of water and $\mathrm{Na}$ in the intestine. Coccus enterotoxins, alongside the toxic substance of virulent syndrome et al., surface unit classified as super microorganism substances to the recognition of antigens in vivo compared to standard antigens [20, 23].

Symptoms: S. aureus disease is characterized by a brief period, usually $2-4$ hours. The onset is explosive and is characterized by forcing and symptoms but no fever. The discomfort only lasts twelve hours. In severe cases, dehydration, hidden complexion and collapse may require an (intravenous) infusion. The short incubation period of the area unites the characteristics of intoxication wherever discomfort is the result of the absorption of the preformed toxic substance in the food [10].

Detection of organisms: The presence of an oversized variety of S. aureus organisms in very clean food indicates poor handling or hygiene. The dilution is placed on Baird-parker agar or Sonitrol salt agar. Cytotoxins are often detected and known by gel diffusion [18, 20].

Prevention and control: The discomfort of food-borne microorganisms per unit area of microorganisms is generally avoided and controlled by proper cooking and preparation of food while being preserved. For example, adequate refrigeration of food, improving personal hygiene, proper cooking and the heating process. The technique or management measures also include:

a) The education of these United Nations agencies prepares the reception of food and the various food handlers so that they must demand correct personal measures.

b) Prohibit people who are absent or have different skin lesions from handling food.

c) Place the food in a cold place at four degrees centigrade or less from all the food so as to stop the multiplication of microorganisms and also the formation of toxic substances. Food should be uninterrupted at temperature for as short a time as possible [24].

\section{Clostridium botulinum:}

Etiology: the true bacterium is a gram-positive anaerobic reproductive structure carrying cosmopolitan bacilli in the soil, sediments of lake ponds and decaying vegetation. Seven completely different strains of the surface unit of organisms (A - G) classified supported the specificity of medical science and different neurolysins. Most rumors are of a human outbreak zone unit linked to fish and food. gastrointestinal disorders in animals are mainly due to types C and D and hardly to types A and B. All the strains producing toxins are placed in at least one of the 4 groups; I, II, III, and IV. group I contains proteolytic, group II the 
non-proteolytic type and group IV of the medical sciences G. group III consists of types C and D [25]. Epidemiology: gastrointestinal disorder has no geographic boundaries. scattered outbreaks occur in most countries. The sources of exposure to the toxic substance and the risk of dissidence of the disease between regions are attributable to the distinction between storage, feeding, and food management practices, epidemics linked to the absorption of toxic substances in the discovered feed unit discovered a standard unit in the northern USA from America and Europe wherever outbreaks in animals on pastures have been reported mainly in South Africa, Australia and at the seaside in the United States [18].

Pathogenesis: throughout their growth, the strains of real bacteria produce very powerful neurolysin which causes neuroparalytic diseases called gastrointestinal disorders in humans and animals without being the case of a histological lesion. A gastrointestinal disorder can lead to death due to muscle dysfunction of metastases unless it is treated properly. toxic gastrointestinal disorder, a toxic substance is absorbed by the abdomen of the organ and the anterior intestine or wound, carried by the bloodstream to the receptor and enters the vegetative cell when the receptor mediates endocytosis the peripheral cholinergic nerve endings with the myoneural junction, the neuronal structure, the parasympathetic end, and peripheral neuronal structure. The important chain of the toxic substance is to blame for the binding to the receptor and the translocation in the cell and also the light chain of the toxic substance for the blocking resulting from the discharge of the neurotransmitter at the myoneural junction, then inflicting a nervous disorder by due to the lack of neurotransmitters (acetylcholine) and have an effect on the muscle of respiration, then death from metastatic insufficiency [26].

Detection of toxic substance: biological test of victimization in mice in addition to neutralization of the toxic substance with polyvalent antitoxins used, but the sensitivity is low in each ruminant and each horse because they are considerably more sensitive than the mice to gastro disorders -intestinal toxic substance Protection with the monovalent toxin makes it possible to sort out the toxins concerned. the detection of toxic substances by dosage control seems less sensitive than the biological assay on mice [26].

Prevention and control: The toxic substance performed in food will be completely destroyed by exposure to a temperature of $80^{\circ} \mathrm{C}$ for half an hour or boiling for ten minutes. Therefore, all foods low in canned homo acid should be simmered before being eaten for consumption. ne'er style food if its associated degree of smell shows gas formation. interference from foodborne gastrointestinal disorders also depends on ensuring effective management of the commercial units in the commercial canned food area destroying all spores of gastrointestinal disorders $\mathrm{C}$. this requires cooking at $121{ }^{\circ} \mathrm{C}$ or higher. Vegetables that are kept at home should be simmered and stirred for at least three minutes before serving to destroy toxins from gastrointestinal upset. Foods with an apparent odor or a suspected odor should not be opened [27].

\section{Escherichia coli:}

Etiology: microorganism of the escherichia surface unit (E. coli) which belongs to the family of enterobacteria and the gramnegative rod of the surface unit up to three $\mu \mathrm{m}$ long, ferments the aldohexose and a wide selection of sugars. These Lactaid fermenters produce pink colonies on Mcconkey agar. hemolytic activity on nutrient agar is characteristic of the bound strain of E. coli. It is mobile with covered and sometimes rough flagella [27,20]. 0157: H7, the first serotype recognized as a cause of human discomfort. E. coli 0157: H7 is one of sixty vertex serotypes in production. E. coli which causes a series of human discomforts like delicate symptoms, damages inflammation and hemolytic uremic syndrome (HUS) [21].

Epidemiology: enterohemorrhagic E. coli and manufacturing unit of E. Coli manufacturing verocytotoxins are being recovered in humans and animals and represent a major foodborne illness. E. coli 0157: H7, is a crucial component of the serotype and appears to predominate in most regions. Strains producing a toxic Shiga- type unit (SLT) that produce symptoms in humans and animals. In most cases, the area unit of cows represents the largest reservoir of E. Coli. E. coli 0157: H7, is a transient inhabitant of the epithelial canal of a ruminant usually. The contribution of infection is the contamination of food by human and animal excrement. The organization will continue the manure, the water tank and various farm locations. The association of E. Coli 0157: H7 with meat, under grilled beef and milk, has led to studying the role of cows as a reservoir of pathogens [28].

Pathogenesis: the enterohemorrhagic E. coli strain (EHEC) can manufacture one or more styles of cytotoxins that the surface unit collects called Shiga-type toxic substances (SLT) because they are antigenically and functionally like the Shiga toxin created by enteric bacteria dysenteric. SLI was previously called verotoxin. The toxins cause cell secretion and kill cells in colonic animal tissue. An enterohemorrhagic E. coli zone unit characterized by the presence of SLTS genes, a locus for the erasure of enterocytes (LEE) and a better inclusion body of molecular weight which codes for an erythrolysin. These 3 virulence factors are unitary donations in most of the E. coli linked to bloody symptoms and to the crisis of hemolytic pathology in humans [18].

Symptoms: the period is 72 to 120 hours. The clinical sign at the start could also be a symptom with abdominal cramps, which can turn a bloody symptom in a few days. there is no fever. Symptoms of the unity of the E. coli septicemia zone are mainly due to bacteremia, final toxemia and also the result of the localization of microorganisms in a kind of tissue area of the whole body [14]. 
Detection of toxins: laboratory diagnostics involve growing food on Macconkey agar or sorbitol, Macconkey agar, wherever they do not ferment sorbitol. The strains are often then known by the serotyping of antisera specific to victimization. SLTs are often detected by assay and cistron writing for them is often detected by deoxyribonucleic acid hybridization techniques [16]. Prevention and Control: The prevention/avoidance of foodborne illness caused by E. coli is often prevented by constant technique as the interference of different foodborne illnesses caused by a microorganism. However, due to the results for young children, special care is required to watch. this organism's sensitivity to heat should not occur when food is properly grilled. in the case of beef, it is advisable to grill it at $160^{\circ} \mathrm{F}$ or for the core temperature to be delivered at a minimum of $1555^{\circ} \mathrm{C}$ for at least 15 seconds, which the juice zone unit releases. Attributable to the unevenness of food cooking at $155-160{ }^{\circ} \mathrm{F}$ provides a life of safety. Once grilled, meats should not be ordered between $40^{\circ} \mathrm{F}$ and $140^{\circ} \mathrm{F}$ for 3 to 4 hours [24].

\section{Shigella:}

Etiology: Enteric bacteria could be a species of eubacteria that cause disease in humans and different primates. Enteric bacteria are gram-negative rods that form a non-mobile, non-spore forming unit. The microorganism zone unit is primarily someone's disease but has been found in some primates. Shigellas are optional unitary anaerobes, like eubacteria like E coli [27,18].

Epidemiology: Transmission of enteric bacteria will occur through direct person-to-person deployment or from contaminated food and water. The least infectious dose is often transmitted directly from contaminated fingers since intermediate replication of microorganisms is not necessary to reach the low infectious dose. In developed countries, most of the surface units transmitted via the fecal-oral route occur in individuals with symptomatic infection. In developing countries, each fecal-oral course and contamination of common food and water provide vital mechanisms for uniting the symptoms of transmission [18]. Pathogenesis: the enteric bacteria attach and penetrate the cell walls of the internal organs of the small intestines by producing toxins that will promote the symptoms characteristic of the disease. The toxic substance Shiga allows the microorganism to enter the lining of animal tissue in the intestines, causing the lining to rupture and hemorrhage. Shigellas even have adhesins that promote binding to vegetative cell surfaces and inclusion body antigens by the invasion that allow the microorganism to enter target cells, thereby increasing its virulence [28].

Symptoms: Abdominal pain, cramps, diarrhea, fever, vomiting, blood, pus, or secretions in the stool and muscle spasm area are common symptoms. delicate infections cause a lower fever (about one hundred to $102^{\circ} \mathrm{F}$ (38 to thirty-eight, $9^{\circ} \mathrm{C}$ ) and an aqueous symptom one to two days when individuals ingest the microorganism (29). Detection of toxin: enteric bacterial infection is diagnosed by analyzing a stool sample. Initially, a stool sample must be obtained from the potentially infected person, and therefore the sample is placed on a medium to encourage the expansion of the microorganism. If and once there is growth, the surface unit of the microorganism is known, usually by looking at the expansion under a magnifying glass [28]. interference and control: enteric bacteria are sensitive to heat and can be killed by intense heat (over $70^{\circ} \mathrm{C}$ ). undercooked meat or food and cross-contamination, once barbecue material comes into contact with raw manufacturing or contaminated material (cutting boards), the area unit is the biggest cause of infection. proper handling of kitchen and hygienic food will, therefore, prevent excessive enteric bacterial infections. There is currently no immunogen for interference from bacillary dysentery, but there is a current analysis that looks promising. The most effective technique for interfering is frequent and vigorous hand washing with heat, cleaner water, and ensuring proper and properly disposed of sources of drinking water in developing countries [30].

\section{Campylobacter:}

Etiology: Campylobacteriosis is an associated infection caused by a microorganism of the genus Campylobacter. There is a surface unit of approximately sixteen species related to Campylobacter, but the most isolated zone unit usually $C$. jejuni, $C$. coli and C. upsaliensis. C. jejuni is the main species currently linked to the human malaise. Campylobacter was also responsible for August 15, 1945, for hospitalizations linked to food-borne illnesses and on June 6, 1944, for deaths linked to food-borne illnesses $[18,27]$.

Epidemiology: Campylobacter is one of the leading causes of stomach flu in human microorganisms. An oversized animal tank is still a gift, with up to 100 percent of poultry, as well as chickens, turkeys, and water birds, having well infections in their internal organic pathways. Infected chicken droppings can contain up to 109 microorganisms per twenty-five grams, and due to the facilities, the microorganism zone unit is unfolded into different chickens. This greatly exceeds the infectious dose of 1,000 to 10,000 microorganisms for humans [20]. Pathogenesis: motility of microorganisms, the formation of secretions, production of toxic substances, fixation, acquisition, and unit of translocation surface among the processes linked to the virulence of $C$. jejuni. Infection begins with the absorption of $C$. jejuni from contaminated food or water. viscous acid provides a barrier, and the microorganism should also reach the tiny and huge intestines to multiply; $C$. jejuni invades every animal tissue cell and the cells inside the propria plate [28].

Symptoms: The symptoms associated with this unit of the disease zone generally resemble those of the flu: fever, nausea, abdominal cramps, vomiting, enteritis, diarrhea and malaise, symptoms begin within 2 to 5 days following the absorption of the microorganism, and discomfort usually lasts 7-10 days. the return of this disease will occur up to a few months when the absorption of the infectious agent. different complications will include infectious diseases, respiratory tract infections and shortterm reactive inflammatory diseases [28]. Detection of toxin: attributable to the distinctive growth characteristics of Campylobacter, the isolation of these organisms from field samples requires the use of special culture media and conditions. 
Campylobacter jejuni and Campylobacter coli are often isolated from the intestines of healthy animals, poultry, pets, farm animals and wild birds, the designation of $C$. jejuni are based on the organism's isolation from environments selective under small aerobic conditions. The PCR-based method allows an effective area unit in distinctive infection, mainly if culture is difficult or if the sample has been somewhat mismanaged. However, a positive control is not comfortable evidence to see a feat and should be thought of in conjunction with clinical signs [27]. Interference and management: control depends on sanitation and hygiene in livestock buildings to reduce the populations of microorganisms in the atmosphere of animals. The quantity of organisms is often reduced and controlled in meat processing plants by victimization Risk analysis of essential management points as well as washing, handling and cooling of carcasses, improvement of food-handling skills in restaurants and in the family room can reduce the transmission of the organism and the proper cooking of meat like poultry at a closed temperature of $82{ }^{\circ} \mathrm{C}$ can eliminate the organism [31].

\section{CONCLUSION:}

Foodborne bacterial diseases which, like the return of poultry to the meat zone, are among the most widespread global public health problems of recent times, and their implication for health and the economy is growing more recognized. However, the impact of the truth on microorganisms of foodborne illness is unknown for a variety of reasons, as well as the weak responses of victims in interviews with health workers, misdiagnosis of discomfort, inadequate assortment samples for laboratory analysis and improper laboratory examination. The presence of various morbid microorganisms in many foods presents a danger and an increase in considerations regarding the protection of these food products. Besides, there is a desire to implement strict sanitary measures in the context of production, handling, storage like the HACCP program and ISO - 22000 for safe food and the food trade to guarantee the standard of these foods to minimize or eliminate the risk of FBI and microorganism.

\section{Conflict of interest}

The authors declare no conflicts of interest.

Acknowledgment

The authors acknowledge assistance from the Dept. of Biological Sciences, Faculty of Science, King Abdulaziz University (KAU), Jeddah, KSA.

\section{REFERENCES:}

1. Rasschaert G, Houf K, Godard C, Wildemauwe C, Pastuszczak-Frak M, De Zutter L. Contamination of carcasses with Salmonella during poultry slaughter. Journal of Food Protection 2008;71(1):146-152.

2. Scallan E, Hoekstra RM, Angulo FJ, Tauxe RV, Widdowson MA, Roy SL, et al. Foodborne illness acquired in the United States - major pathogens. Emerging Infectious Diseases 2011;17(1):7-15.

3. Silva MP, Cavalli DR, Oliveira TCRM. Avaliação do padrão de coliforms a $45^{\circ} \mathrm{C}$ e comparação da eficiência das técnicas dos tubos múltiplose Petrifilm EC na detecção de coliformes totais e Escherichiacoli em alimentos. Ciência e Tecnologia de Alimentos 2006;26(2):352-359.

4. Amélie Rouger, Odile Tresse, and Monique Zagorec' Bacterial Contaminants of Poultry Meat: Sources, Species, and Dynamics, Microorganisms. 2017 Sep; 5(3): 50.

5. La Volaille Française Actualités 2017. Tout Savoir sur la Volaille Française, accessed, pp 1-3. Filières Agricoles et de la Pêche et Aquaculture, accessed on 24 July 2017.

6. Authority E.F.S. The European Union summary report on trends and sources of zoonoses, zoonotic agents and foodborne outbreaks in 2015. EFSA. J. 2016; 14:4634.

7. Poultry: the most common food in outbreaks with known pathogens, United States, 1998-2012.

8. Poultry: the most common food in outbreaks with known pathogens, United States, 1998-2012.

9. Adams M, Moss M (2008) Food microbiology (3rdedtn), UK RSC press, 252-256.

10. Center for disease Control and presentation (2011) Estimates of food borne Illness in the United States.

11. Bean NH, Griffins PM (1990) Foodborne Disease Outbreaks in the United States, 1973-1987: Pathogens, Vehicles, and Trends. J Food Microbial 53:804-817.

12. http://www.cdc.gov/.

13. Bryan FL (1994) Microbiological food hazards based on epidemiological information; Food Techno 28:52.

14. Le Minor, Popoff MP (1987) Designation of salmonella enteric species, nom, rev., as the type and only species of the genus salmonella. Int J Syst Evol Micr 37:465-468.

15. Gracey LF, Collins DS (1992) Food poisoning salmonella surveillance in meat hygiene. (9thestn) Bailliere, Tindal, London.

16. Kalpelmecher K (1993) the role of salmonella in food borne diseases: In microbiological quality of foods. New York Academic press.

17. Radostits OM, Gay, Hinchlif, Constable PD (2007) Veterinary medicine text book of Disease of Cattle, Horses, Sheep, Pig and Goats. (1Othedtn), Saunders, Philadelphia. 
18. Acha PN, Sayfres B (2001) Salmonellosis: in: zoonoses and communicable disease Common to man and animal. (3rdedtn), Pan American Health Organization, USA.

19. Quinn PJ, Markey BK, Carter ME, Demnelly WJ. Leonard FC (2001) Veterinary microbiology and microbial disease. (Bthedit) Blackwell publishing, Oxford, UK.

20. Bryan FL, Mckiley TW, Mixon (1971) Use of time temperature evaluations in detecting the responsible Vehicles and contributing factors food born disease outbreaks. Journal of Milk Food Techno, 34:576 - 582.

21. Walderhaug M (2007) Food borne pathogenic microorganisms and natural foXIns. Food and Drug Administration, Center for Food Safety and Applied Nutrition, 28:48-65.

22. Anderson K, Pritchard D (2008) An Update on Staphylococcus aurous Mastitis. (4theatn), Benjamin/ Cummings Publishing Company.

23. World Health Organization (2008) Food borne disease outbreaks: guide line for integration and control.

24. Hall JD, McCroskey LM, Pincom BJ, Hathaway CL (1985) Isolation of an organism resembilin. J Clin Microbiol 21:654-655.

25. Hirsh DC, Macalchian J, Walker RL (2004) Botulism, In Veterinary Microbiology.

26. Jay JM (2000) Modern food microbiology (6thedtn), Aspen Publications Gaithersburg, Maryland.

27. Meat Consumption (Indicator); accessed on 24 July 2017.

28. Scallan E, Hoekstra RM, Angulo FJ, Tauxe RV, Widdowson MA, ET AL. (2011) Foodborne illness acquired in the United States-major pathogens.

29. Mead PS, Slutsker L, Dietz V, McCaig LF, Bresee JS, et al. (1999) Food-related illiness and death in the United States. Emerg Infect Dis 5: 607-625.

30. World Health Organization (2008). Food borne disease outbreaks: guide line for integration and control. 